\title{
Cyclical causalities between the U.S. wholesale beef and feed prices: A Markov-switching approach
}

\author{
Dicle Ozdemir \\ Mugla Sitki Kocman University, Turkey
}

Received: 10 November 2019

Revised: 29 January 2020

Accepted: 3 February 2020

\begin{abstract}
The purpose of this study is to assess the feed price driven dynamics of the U.S. wholesale beef prices in which regime switches are induced by transitions between Markov regimes. By allowing the transition probabilities to vary according to some main grain feed prices, we examine if the regime transition probabilities vary over time under two different states of the growth rate of beef prices as "low-mean growth" and "high-mean growth" price regimes. The results show that when the prices are in high-mean growth regime, the probability that it will remain in this regime is greater than that it will switch to low-mean regime. This findings also indicate that livestock feed prices provides some predicted power to the model of beef price regime switching process and supports livestock feed prices contributing to whether the beef price levels remains in low/high-mean regime. By employing Markov switching dynamic regression model, we also find that all types of the feed prices have a significant effect on the beef prices in low-growth regime, but only the prices of hay and sorghum significantly affect the beef prices in the high-growth regime.
\end{abstract}

Keywords: agricultural commodity; Markov switching; feed price; red meat market JEL Classification Codes: E10, E31, E32, Q11

\section{Introduction}

The value of U.S. livestock production output and U.S. farmers play an important role by ensuring a safe and reliable food supply. Furthermore, United States is also the largest feed producer country in North America and production is mostly carried out in chicken, beef and pork feed and usually in integrated facilities. In the US, animal feeds are produced in the form of primary feed by advanced technology in the high-capacity production facilities. Since feed is the largest cost of producing livestock and poultry production, which may account for $60 \%$ $70 \%$ of total live stock production costs in most years, total feed grain costs plays an important

\footnotetext{
*E-mail: dicleozdemir@mu.edu.tr.

Citation: Ozdemir, Dicle (2020) Cyclical causalities between U.S. wholesale beef and feed prices: A Markovswitching approach, Economics and Business Letters, 9(2), 135-145.
}

DOI: 10.17811/ebl.9.2.2020.135-145 
role for the livelihoods of farmers for both livestock producers under any size of scale and meat retailers. Generally, higher grain prices take a toll on the livestock sectors as higher feed costs and will eventually have to be reflected in higher prices for beef (Lawrence et all, 2008).

Theoretically, in the formation of red meat prices, the response of the retail prices of red meat to changes in their price of feed is crucially important. Specifically, the existence of price asymmetries indicate that changes in feed grain prices could lead to changes in retail meat prices asymmetrically; that is, the price changes at the livestock production process due to changes in production costs are not passed to red meat prices changes at the retail level in a regular time manner. If feed grain and red meat price data exhibits asymmetric price cycles and structural regime shifts, then constant mean, autoregressive parameters, and variance under a linear framework will not be suitable. Therefore, to understand the cyclical asymmetries between meat and feed prices and to investigate whether feed prices have contributed to wholesale red meat prices in the U.S. over the past 20 years, we assume Hamilton's (1989) Markov-switching vector autoregressive (MS-AR) model to capture nonlinear dynamics and detect the mean rate of price changes associated to a low and high-mean regime. This study contributes to the literature by examining the effect of cyclical fluctuations of cattle feed prices on the regime behavior of wholesale beef prices in the U.S. by employing the Markov switching model with TVTP and Markov switching dynamic regression model. The results show that two types of growth regimes could be identified in the U.S. wholesale beef market. Furthermore, in the second step by using Markov switching dynamic regression model, we estimate the effects and contribution of the feed prices to the growth rate of beef prices in a cyclical diversification. This paper is structured as follows: Section 2 includes a literature review. Section 3 provides detailed information on the method and the data of this study, section 4 discusses the empirical results. Conclusion of this study is in section 5 .

\section{Literature review}

Regime switching is a time series model in which parameters are allowed switching in the parameters for any number of explanatory variables and have become a powerful dynamic regression analysis of time series for applied studies. The switching regimes were obtained by allowing the turning of parameters and switching these parameters between regimes. Goldfeld and Quandt (1973) introduced a useful version of the models, in which regression models with Markov Switching are developed to capture discrete changes in economic system. Another modification of the regression models with Markov switching developed by Lee and Porter (1984), Cosslett and Lee (1985), Hamilton (1989), Cai (1994), Hamilton and Susmel (1994), Engel and Hakkio (1993), Bekaert and Hodrick (2001), Edwards and Susmel (2003), Moolman (2004), Brunetti et al. (2007), Moore and Wang (2007), Chen et al. (2012) and Reyes-Heroles and Tenorio (2017). We investigate whether feed prices have a contribution to the U.S. wholesale meat price cycles' turning points using an extended version of Markov switching model by Filardo's (1994) time varying transition probability model in which the transition probabilities of the chain vary along time.

A number of researchers have investigated price fluctuations in agricultural markets. Ball \& Mankiw (1994) report positive nominal price shocks have higher efficiency than negative price shocks due to input price reductions and the real value of margin in the presence of inflation. Buckle \& Carlson (2000) examined the direction of price change in the last three months has been up, same, or down using a business survey in New Zealand and they report that large companies often have price adjustment advantages over small companies. CSC Tejeda and Goodwin (2009) show that steadily rising corn prices, due to mandated ethanol production, lead to rising sorghum prices. Bastianin, Galeotti and Manera (2013) find no evidence for linkages between ethanol and cattle prices. Ceballos et al. (2015) used GARCH model to study the transmission mechanism of international grain prices on the domestic food price in 27 developing 
countries and show grain price volatility is most likely to be transmitted to domestic markets for wheat, followed by rice and then maize. Schulte and Musshof (2018) find support for the hypothesis that feed prices are perfectly transmitted across regions and independently from feed scandals and type of feed.

This study is to consider the nonlinear effects of feed grain prices to red meat wholesale prices and their asymmetric behavior in the U.S by applying time-varying transition probabilities (TVTP) and Markov switching dynamic regression model.

\section{Method and data}

Autoregressive models are popular in economics and in other sciences because they are flexible and respond more to their own past values than distributed lag models. The same is likely true for the Markov Switching Autoregressive Model (MS-AR), proposed by Hamilton (1989) and extended by Filardo (1994). In his pioneering work, Hamilton (1989) developed Markov switching autoregressive model to test for regime switching with constant transition probabilities. Since regime switching models with time varying transition probabilities allow these probabilities to evolve as observable economic or financial variables, Filardo's (1994) TVTP models allows the transition probabilities to decrease or increase after a change of regime. Hamilton (1989)'s model fixed transition probabilities assumes that the transition probabilities are time-invariant; that is, the expected durations of regimes do not vary over time. The model, switches between the different states or regimes that cannot actually be observed but is determined by an underlying stochastic process, is discrete-valued following transition probabilities. The simplest time series model for a discrete-valued random variable is a K-state Markov chain, ruled by an unobservable variable. This unobservable variable, denoted as $\left(S_{t}\right)$, is supposed to represent the current state of the economy. Generally, a 2-state Markov chain is preferred in applications, that is, for all $t, S_{t}$ takes value 1 when the economy is in expansion and value 2 when the economy is in recession. If we take into account a two regime Markov switching model, the regression is expressed as (Hamilton, 1989):

$$
\begin{gathered}
y_{t}=s_{t} \mu_{1}+\left(1-s_{t}\right) \mu_{2}+\phi y_{t-1}+\varepsilon_{t} \\
\mu_{s t}=\left\{\begin{array}{l}
\mu_{1} \text { if } \mathrm{S}_{t}=1 \text { (high-mean regime) } \\
\mu_{2} \text { if } \mathrm{S}_{t}=2 \text { (low-mean regime) }
\end{array}\right.
\end{gathered}
$$

where $\mu_{s t}$, is the estimated regime dependent intercept and $\mathrm{S}_{\mathrm{t}}$ is the regime variable which is equal to 1 if the process is in state 1 , and is equal to 2 if it is in regime 2 . In a two regime autoregressive model of order 4, the model can be expressed as (Hamilton, 1989):

$$
\begin{array}{r}
Y_{t}=\mu_{s_{t}}+\sum_{k=1}^{p} \phi_{j}\left(Y_{t-k}-\mu_{s_{t-k}}\right)+\varepsilon_{t} \\
\varepsilon_{t} \mid s_{t} \sim \operatorname{NID}\left(0, \sigma^{2}\right) \text { and } s_{t}=1,2
\end{array}
$$

where, $\mathrm{p}$ is the order of autoregressive coefficients, $\sigma_{s t}$ is the standard deviation, $\phi_{s t}$ shows the autoregressive coefficients and $\varepsilon_{t}$ are the residuals characterized as a random variable of zeromean and constant variance. In this study, we consider a two-regime Markov-switching model of AR(4) autoregressive order based on the statistical significance of the lags and on the results of the normality, heteroscedasticity, and serial correlation tests. $S_{t}$ is unobserved random variable and follow a particular stochastic process, following a first-order Markov chain. If we assume that the $S_{t}$ is a random variable which only can be 1 or 2 , the regime $S_{t}=2$ is identified as low-mean regime and the regime $S_{t}=1$ is high-mean regime. The change from $S_{t}=1$ to $S_{t}=2$ is governed by a first order two-state Markov process with fixed transition probabilities, demonstrated as: 


$$
P\left(S_{t}=j \mid S_{t-1}=i, S_{t-2}=q, \ldots, Y_{t-1}, Y_{t-2}, \ldots\right)=P\left(S_{t}=j \mid S_{t-1}=i,\right)=p_{i j}
$$

and $p_{i j}$ is the probability of staying in regime $j$ in period $t$, if regime $i$ occurs in period $t-1$. This probability is called the smoother probability and can also be calculated for both states. If the probability for $S_{t}$ depends on $S_{t-1}$, the transition probability matrix measures the persistence in the regime and can be defined as follows:

$$
P=\left(\begin{array}{ll}
p_{11} & p_{12} \\
p_{21} & p_{22}
\end{array}\right)
$$

where $p_{11}$ is the probability that $\mathrm{y}_{\mathrm{t}}$, which is currently in regime 1 , will remain in regime $1 ; p_{22}$ is the probability that $\mathrm{y}_{\mathrm{t}}$, which is currently in regime 2 , will remain in regime $2 ; p_{12}$ is the probability of switching from state 1 to state 2 in period $t$; and $p_{21}$ is the probability of switching from state 2 to state 1 in period $t$.

The original Hamilton (1989) model assumes that the regime switching probabilities are invariant with time; consequently, the model is restrictive to examine the behavior of macroeconomic or financial variables. Therefore, we implemented an extended MarkovSwitching estimation procedure with time-varying transition probabilities in Markov chain, as explained by Filardo (1994) and Diebold et al. (1994), in which transition probabilities depend on the behavior of other macroeconomic variables. The regime-switching process, under a firstorder Markov-chain and affected by the information variable $\left(Z_{t}\right)$, characterized by timevarying transition probabilities (TVTP), is described as follows:

$$
\begin{aligned}
& p\left[s_{t}=1 \mid s_{t-1}=1\right]=p_{11}\left(z_{t}\right), \\
& p\left[s_{t}=1 \mid s_{t-1}=2\right]=p_{21}\left(z_{t}\right), \\
& p\left[s_{t}=2 \mid s_{t-1}=1\right]=p_{12}\left(z_{t}\right), \\
& p\left[s_{t}=2 \mid s_{t-1}=2\right]=p_{22}\left(z_{t}\right),
\end{aligned}
$$

where $z_{t}$ is the information variable that affect the mean or volatility. In our study, we use the main four livestock feed prices as proxy of $z_{t}$ whereby each $Z$ vector includes the lagged values of corn, barley, hay and sorghum prices, respectively. The transition probabilities are modelled as a logistictical functional form such as:

$$
p\left(z_{t}\right)=\frac{\exp \left(\theta_{p 1}+\theta_{p 2} z_{t-1}\right)}{1+\exp \left(\theta_{p 1}+\theta_{p 2} z_{t-1}\right)}
$$

and

$$
q\left(z_{t}\right)=\frac{\exp \left(\theta_{q 1}+\theta_{q 2} z_{t-1}\right)}{1+\exp \left(\theta_{q 1}+\theta_{q 2} z_{t-1}\right)}
$$

where $z_{t-1}$ is the lagged feed price variables, $\theta_{1}$ and $\theta_{2}$ are the coefficients that determine the effect of the $z_{t-1}$ on the time variation of $\mathrm{p}$ and $\mathrm{q}$ respectively.

The above models are estimated with four main livestock real feed grain prices (base January $2000=100$ ) received by farmers, including corn gluten feed (dollars per ton), sorghum feed (dollars per bushel), hay alfalfa (dollars per ton) barley feed (dollars per bushel) and finally average wholesale price of boxed beef cut-out ( $\$ / \mathrm{cwt}$, dressed basis). Figure 1 shows all the series in real values from 2000M1 to 2018 M3. All data are taken from The United States Department of Agriculture (USDA). 
Figure 1. Wholesale beef price and major livestock feed prices.

BEEF

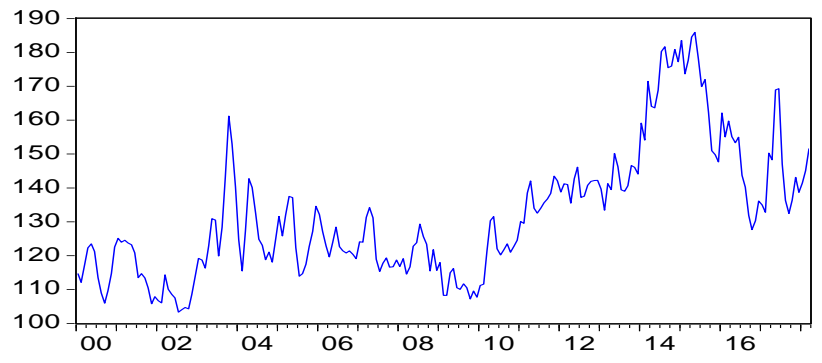

SORGHUM

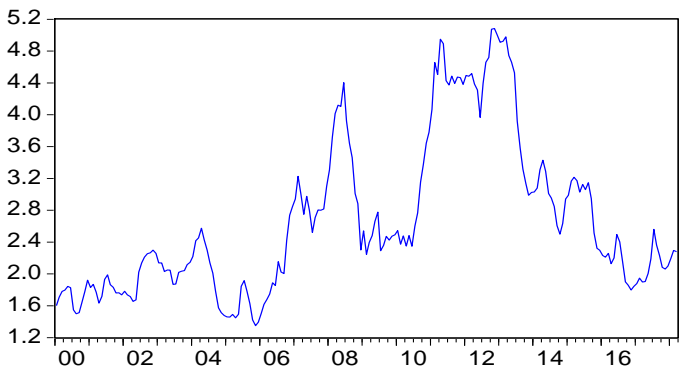

CORN

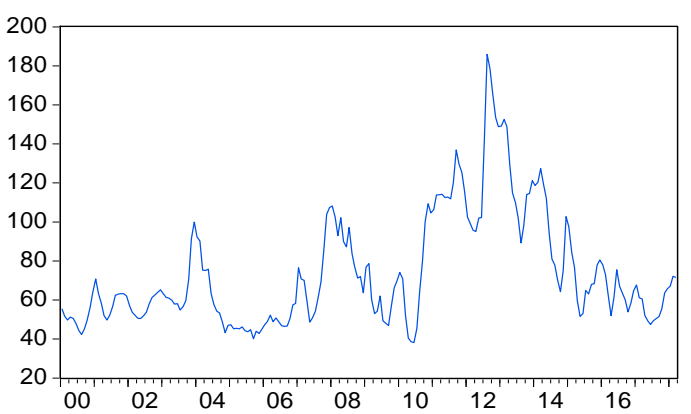

HAY

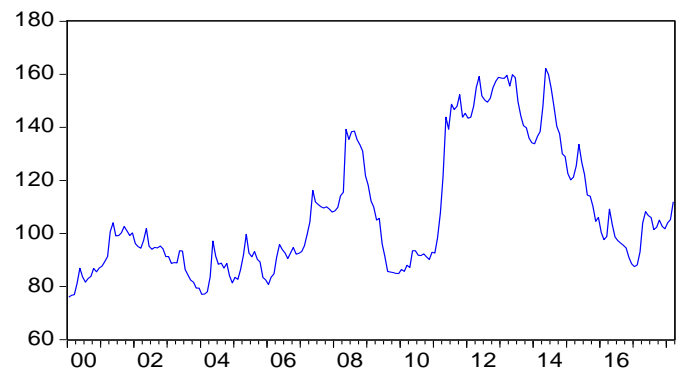

BARLEY

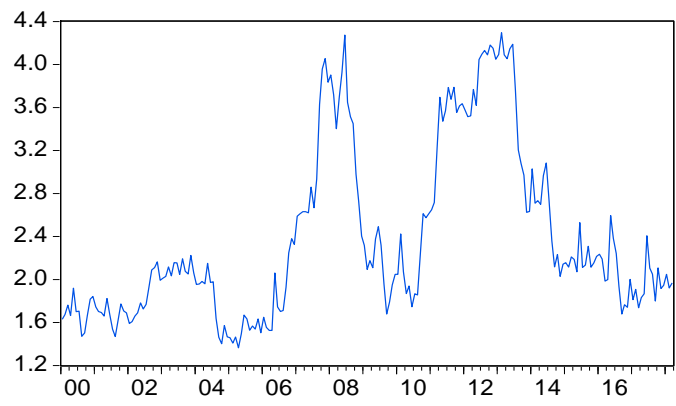

Source. U.S. Department of Agriculture (2019).

\section{Empirical results}

Table 1 summarizes the descriptive statistics of beef, hay sorghum, corn and barley real price series. Since the data used in this study is monthly, to determine optimal lag selection, we use the Akaike information criterion (AIC) in selecting the lag length. Based on the statistical significance of the lags and on the results of the normality, heteroscedasticity, and serial correlation tests, AR(4) model is found to be the most suitable unconditional mean model, since the series fluctuate around its mean.

Using augmented Dickey-Fuller (ADF) statistic (the results of which shown in Table 2, since we determined the existence of unit root in all variables as seen in Table 2, we convert all the data into the first difference of logarithms; then the series become stationary. All the variables under this study are transformed into logarithmic values. 
Table 1. Descriptive statistics of the data.

\begin{tabular}{lrrrrr}
\hline \hline & Beef & Hay & Sorghum & Corn & Barley \\
\hline \hline Mean & 132.1327 & 107.8485 & 2.673772 & 74.21232 & 2.384643 \\
Median & 127.6907 & 99.19549 & 2.373368 & 63.53975 & 2.109196 \\
Maximum & 185.9289 & 162.2127 & 5.083781 & 185.9282 & 4.295423 \\
Minimum & 103.3482 & 76.00000 & 1.349443 & 38.19401 & 1.363490 \\
Std. Dev. & 19.14641 & 23.92617 & 0.977332 & 29.14781 & 0.798897 \\
Skewness & 0.910174 & 0.841904 & 0.928329 & 1.305691 & 0.977037 \\
Kurtosis & 3.293668 & 2.419386 & 2.830244 & 4.375317 & 2.731612 \\
Jarque-Bera & 31.02416 & 28.94741 & 31.71846 & 79.48622 & 35.50025 \\
Probability & 0.000000 & 0.000001 & 0.000000 & 0.000000 & 0.000000 \\
Sum & 28937.07 & 23618.83 & 585.5562 & 16252.50 & 522.2368 \\
Sum Sq. Dev. & 79915.52 & 124796.6 & 208.2289 & 185211.6 & 139.1355 \\
Observations & 219 & 219 & 219 & 219 & 219 \\
\hline \hline
\end{tabular}

Table 2. ADF Test Results.

\begin{tabular}{lrrrrr}
\hline \hline & Beef & Hay & Sorghum & Corn & Barley \\
\hline \hline ADF (Level) & -3.438 & -1.764 & -1.492 & -2.080 & -2.418 \\
ADF & $-12.761^{* * *}$ & $-11.309^{* * *}$ & $-11.204^{* * *}$ & $-15.355^{* * *}$ & $-9.692^{* * *}$ \\
(First Difference) & & &
\end{tabular}

Notes. Table 3 reports ADF (Augmented Dickey and Fuller, 1979) unit root tests with trend intercept for the $\log$ levels of the series. $* * *, * *$ and $*$ represent significance at the $1 \%, 5 \%$ and $10 \%$ levels, respectively.

Table 3 reports the means and standard deviations for each variable in each regime along with the coefficients on the transition parameters of TVTP MS(2)-AR(4) model with inclusion of four main livestock feeds. We represent the VAR model parameters as $\mu_{1}, \mu_{2}, \phi_{1}, \phi_{2}, \phi_{3}, \phi_{4}$ and $\sigma$ and the parameters of the transition probability matrix as $\theta_{\mathrm{p} 1}, \theta_{\mathrm{p} 2}, \theta_{\mathrm{q} 1}$ and $\theta_{\mathrm{q} 2}$. For the specifications the model, in accordance with the Akaike Information Criterion (AIC) and Schwarz Criterion (SBC) and also on the fact that Markov switching models are generally based on AR(4) lag length in the literature, we use TVTP-MS-AR(4) specification, which is found to be adequate to make the residuals white noise. The results reported in Table 4 show that two regimes are identifiable which can be labeled as low mean and high mean price regime. According to this, the monthly beef price index for high mean regime $\left(\mathrm{s}_{\mathrm{t}}=1\right.$ and $\left.\mu_{1}\right)$ is positive with an approximate value of $0.2 \%$ and statistically significant. The mean rate estimated for low-mean regime $\left(\mathrm{s}_{\mathrm{t}}=2\right.$ and $\left.\mu_{2}\right)$ is with a range between $-0.01 \%$ and $-0.03 \%$ and statistically significant.

As to the transition matrix parameters for the inclusion of input variables as major livestock feeds in Table $3, \theta_{\mathrm{p} 1}$ proves to be positive and statistically significant, while all the other parameters are statistically insignificant. Intuitively, an increase in feed prices increases the probability of being in a high-mean regime next period. However, since all the transition parameters are not statistically significant, we can only conclude that increases in the feed prices are associated with higher probabilities of remaining in the high mean regime for beef prices.

After estimating the coefficients, we can reveal the transition probabilities of staying in high mean or low mean, as seen in Table 5. Based on the time varying transition probabilities, for all feed prices, the probability values of low mean regime is less than the probability values of high mean regime, indicating that the probability of beef price growth staying in low-mean regime is less than that of being in an high-mean regime. Furthermore, the estimated results show that the probability of beef prices remaining in high-mean regime (low-mean regime) is higher than that of switching into a low-mean regime (high-mean regime). 
Table 3. TVTP-MS Model Results.

\begin{tabular}{|c|c|c|c|c|}
\hline & Hay & Sorghum & Barley & Corn \\
\hline \multicolumn{5}{|l|}{ Regime 1} \\
\hline \multirow[t]{2}{*}{$\mu_{1}$} & $0.002692 * * *$ & $0.001985 * * *$ & $0.002189 * * *$ & $0.002175 * * *$ \\
\hline & $(0.000453)$ & (0.000439) & $(0.000415)$ & $(0.000421)$ \\
\hline \multirow[t]{2}{*}{$\sigma($ sigma $)$} & $-3.111018 * * *$ & -3.103239 & $-3.100179 * * *$ & $-3.100318 * * *$ \\
\hline & (0.051038) & $(0.051321)$ & $(0.051425)$ & (0.051424) \\
\hline \multicolumn{5}{|l|}{ Regime 2} \\
\hline \multirow[t]{2}{*}{$\mu_{2}$} & $-0.003260 * * *$ & $-0.001980 * * *$ & $-0.002064 * * *$ & $-0.002059 * * *$ \\
\hline & (0.000182) & $(0.000175)$ & (0.000166) & (0.000169) \\
\hline \multirow[t]{2}{*}{$\sigma($ sigma $)$} & $-8.670911 * * *$ & $-9.077805 * * *$ & $-8.978842 * * *$ & $-8.983326 * * *$ \\
\hline & $(0.295994)$ & $(0.247433)$ & $(0.210560)$ & $(0.211749)$ \\
\hline \multicolumn{5}{|l|}{ Common } \\
\hline \multirow[t]{2}{*}{$\phi_{1}$} & $0.056283 * * *$ & $-0.007805 * * *$ & $-0.008209 * * *$ & $-0.008186 * * *$ \\
\hline & (0.002093) & $(0.001560)$ & $(0.001611)$ & (0.001610) \\
\hline \multirow[t]{2}{*}{$\phi_{2}$} & $-0.163372 * * *$ & $-0.131663 * * *$ & $-0.132913 * * *$ & $-0.132894 * * *$ \\
\hline & (0.001682) & (0.001689) & $(0.001611)$ & (0.001392) \\
\hline \multirow[t]{2}{*}{$\phi_{3}$} & $-0.192758 * * *$ & $-0.195252 * * *$ & $-0.195435 * * *$ & $-0.195427 * * *$ \\
\hline & $(0.001624)$ & (0.000853) & $(0.000871)$ & (0.000867) \\
\hline \multirow[t]{2}{*}{$\phi_{4}$} & $-0.123630 * * *$ & $-0.103666 * * *$ & $-0.104462 * * *$ & $-0.104466 * * *$ \\
\hline & $(0.001814)$ & $(0.001308)$ & $(0.001147)$ & $(0.001163)$ \\
\hline \multicolumn{5}{|c|}{ Transition Matrix Parameters } \\
\hline \multirow[t]{2}{*}{$\theta \mathrm{p} 1$} & $3.500747 * * *$ & $3.486660 * * *$ & $3.137451 * * *$ & $3.159446 * * *$ \\
\hline & $(0.465591)$ & $(0.564511)$ & $(0.379954)$ & (0.388900) \\
\hline \multirow[t]{2}{*}{$\theta \mathrm{p} 2$} & 14.07980 & -10.50627 & 0.348284 & -1.734921 \\
\hline & $(6.962441)$ & $(7.747528)$ & $(5.273164)$ & $(3.311299)$ \\
\hline \multirow[t]{2}{*}{$\theta \mathrm{q} 1$} & -4.901903 & -0.278410 & -0.901734 & -0.639610 \\
\hline & $(4.380806)$ & $(0.855773)$ & $(0.811096)$ & $(0.670267)$ \\
\hline \multirow[t]{2}{*}{$\theta \mathrm{q} 2$} & 160.6818 & 8.689356 & 2.727188 & 6.952448 \\
\hline & $(139.9410)$ & $(9.954291)$ & $(9.345790)$ & $(9.118307)$ \\
\hline Log-likelihood & 382.3833 & 391.4431 & 390.1600 & 390.5879 \\
\hline
\end{tabular}

Notes: ***,**,* denote statistical significance at the $1 \%, 5 \%, 10 \%$, respectively. Source: by author based on USDA Data (2019)

Table 4. Time-varying Transition Probabilities.

\begin{tabular}{lcccc}
\hline \hline & $P_{11}$ & $P_{12}$ & $P_{21}$ & $P_{22}$ \\
\hline \hline Hay & 0.964169 & 0.035831 & 0.821035 & 0.178965 \\
Sorghum & 0.962148 & 0.037852 & 0.566207 & 0.433793 \\
Barley & 0.958395 & 0.041605 & 0.709030 & 0.290970 \\
Corn & 0.958517 & 0.041483 & 0.640166 & 0.359834 \\
\hline \hline
\end{tabular}

Another important issue would be to which extent rise in feed prices translates into product prices? That is, while higher input prices in agriculture sector translate into cyclical increases and decreases in final food prices worldwide, the question arises to which extent a growth of grain feed prices may be reflected in animal products prices? Historically, feed costs have represented close to 50-70\% of the total cost of beef production (Shike, 2013). However, while increasing feed costs associate higher costs for livestock productions, and hence, higher wholesale and retail beef prices, since the degree of flexibility obviously differs by animal feed grains, farmers can make some adjustments to minimize these costs (Anderson \& Anderson, 2009). Therefore, once we have explained the beef price cyclical probabilities changing with the four types of animal feed grains as business-cycle predictors, we continue with the estimation of a two-state Markov-switching dynamic regression model that allow regimes and the growth rate of feed prices to switch according to a Markov process and includes the lagged value of the growth rate of beef price variable as a common factor for both regimes to capture 
asymmetric (regime dependent) inference for causality. The MS-DR specification follows the dynamic regression model in the specification of the dynamics. Assume the following specification for the growth rate of beef prices (Hamilton, 1989):

$$
\begin{gathered}
\text { Beef }_{t}=\mu_{s t}+\rho \text { Beef }_{t-1}+\phi \text { Corn }_{t}+\gamma \text { Hay }_{t}+\delta \text { Sorghum }_{t}+\eta \text { Barley }_{t} e_{t} \\
e_{t} \sim N\left(0, \sigma^{2}\right)
\end{gathered}
$$

where $\rho$ is constant and $\mu, \phi, \gamma, \delta$ and $\eta$ are regime-dependent. With the one lag included in the model allows us to test for dynamic or causal relationship of the growth rate of beef prices with the growth rate of feed prices. Table 5 shows the Markov switching dynamic regression results under the specification as high-growth regime (Regime 1) and low-growth regime (Regime 2). As seen from the Table 5, the coefficients on the feed prices are all significant in regime 2 , while only the coefficients of the hay and sorghum price levels are significant in regime 1 . That is, all types of the feed prices have a significant effect on the beef prices in regime 2, but only the price of hay and sorghum significantly affect the beef prices in regime 1 . Thus, corn and barley prices seem to be passive when the beef prices are in high-mean growth regime. The output also indicates that hay prices have major impact on the overall cyclical behavior of the U.S. wholesale beef prices.

Table 5. Markov-switching Dynamic Regression Results.

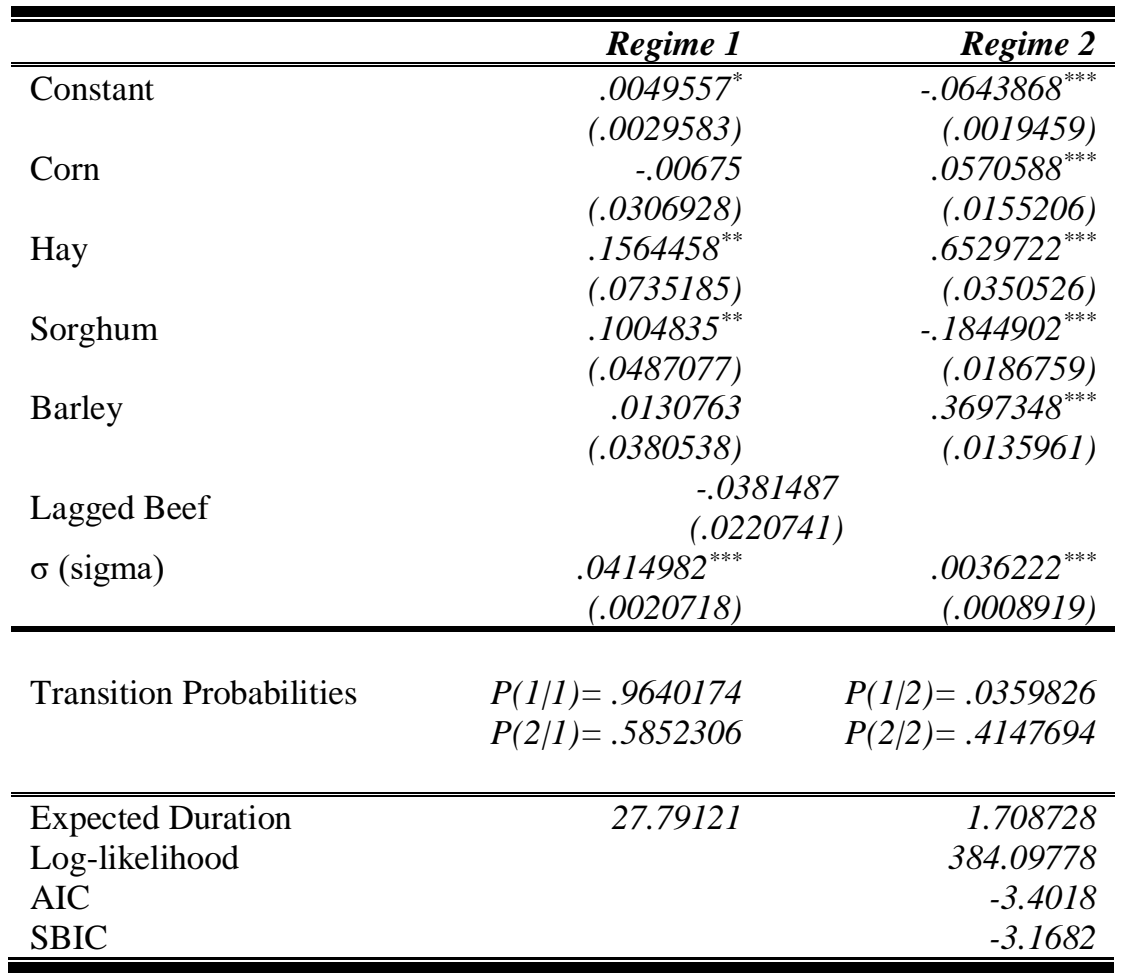

Notes: $* * *, * *, *$ denote statistical significance at the $1 \%, 5 \%, 10 \%$, respectively. Source: by author based on USDA Data (2019)

We plot the smoothed probabilities of being in regime 2 in Figure 2, refers to an estimate of the probability at time $t$ using all the data in the sample; only a few years were in the lowgrowth regimes. We see that the predicted probabilities of being in the low-mean price regime coincide nicely with the lower beef price levels during the whole period. 
Figure 2. Smoothed Probability in Regime 2 (low-mean growth regime).

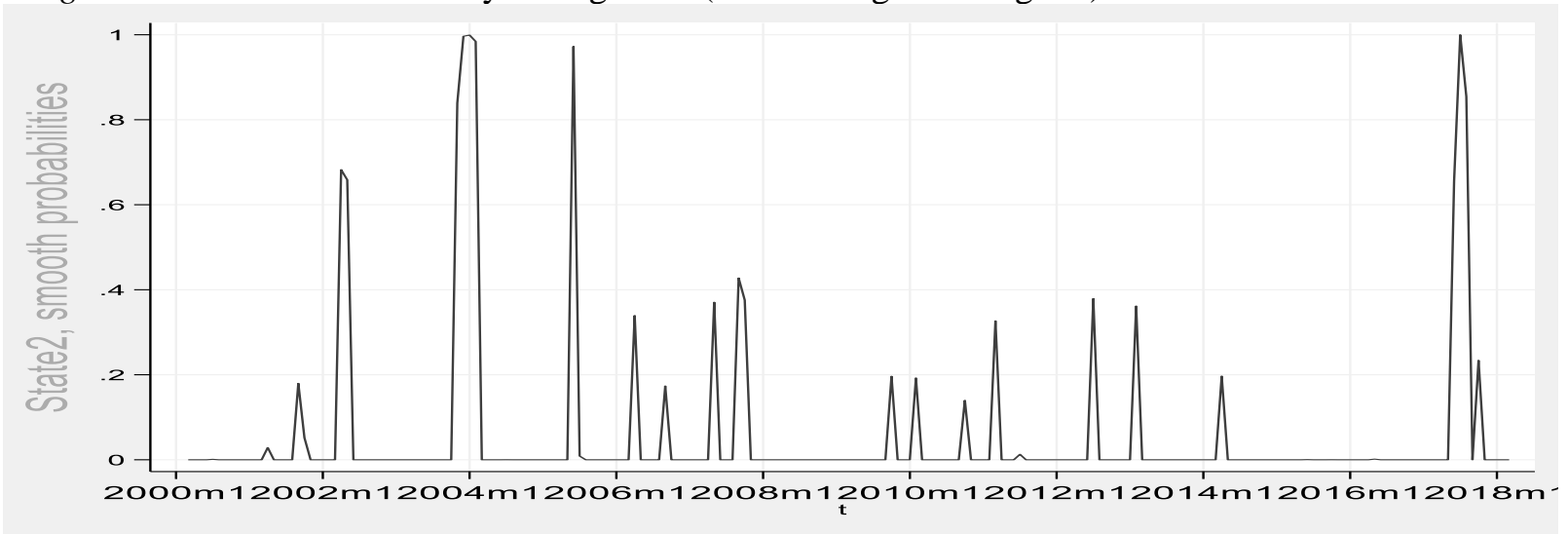

\section{Conclusion}

Understanding the business cycles of input prices in agricultural sector is important as they guide producers improve their awareness regarding production costs and income determination. Fluctuations in livestock feed prices which typically used as an input in livestock production play a major role in red meat market structure determinants and influence the meat prices as well. Evaluation of the price level trend of livestock feed cost is essential for improving efficiencies in the red meat industry and lowering the price of beef products. As beef prices reflect the red meat market trends influenced by feed costs, it is of a crucial importance to analyze the effects of livestock feed prices on U.S. wholesale real beef prices. As with other agriculture products, main livestock feed prices such as barley, hay, sorghum, corn grains fluctuate year-to-year, even month-to-month. As livestock prices are closely related with prices of livestock feeds, it is important to capture the cyclical fluctuations of agricultural sector products to determine business cycle dynamics with accuracy. The basic question is do livestock grain feed prices contribute to beef price cycles?

In this paper, we modeled the real wholesale beef price regime changes in the U.S. using timevarying transition probabilities (TVP) in a Markov switching autoregressive model. By doing this, we allowed transition probabilities to vary with feed price variables to examine the asymmetric influence of feed price variables on the different regimes. The results indicate that grain feed prices contribute to whether the beef prices remain in high-mean regime or not. It is found that an increase (decrease) in the grain feed prices increases (decreases) the probability of remaining in high-mean beef price regime. That is, the probability of transitioning to low or high regimes is likely dependent on the growth rate of feed prices. Furthermore, we use Markov switching dynamic regression model to examine whether the effects of feed prices on beef price movements are regime dependent. The results show that all types of the feed prices have a significant effect on the beef prices in regime 2 , but only the price of hay and sorghum significantly affect the beef prices in regime 1 . Particularly, corn and barley prices seem to be passive when the beef prices are in high-mean growth regime. The results also show that hay prices have major impact on the overall cyclical behavior of the U.S. wholesale beef prices.

\section{References}

Anderson, D. P., and Anderson, J. D. (2009) Food Price Inflation in Livestock Product Markets: From the Live Animal to Retail Prices, paper presented at the International Agricultural Trade Research Consortium, 22-23 June 2009, Seattle, Washington.

Bekaert, G., and Hodrick, R. J. (2001) Expectations Hypotheses Tests, Journal of Finance, 56(4), 1357-1394. 
Ball, L., and Mankiw, N.G. (1994) Asymmetric Price Adjustment and economic Fluctuations, The Economic Journal, 104, 247-261.

Bastianin, A., Galeotti, M., and Manera, M. (2013) Biofuels and food prices: searching for the causal linkm FEEM Working Paper No. 22.

Brunetti, C., Mariano, R. S., Scotti, C., and Tan, A. H. (2007) Markov switching GARCH models of currency turmoil in south-east Asia, Federal Reserve Board, International Finance Discussion Papers, No. 889.

Buckle, R. A., and Carlson, J.A. (2000). Inflation and asymmetric Price Adjustment, Review of Economics and Statistics, 82(1), 157-160.

Cai, J. (1994) A Markov model of switching-regime ARCH, Journal of Business \& Economic Statistics, 12(3), 309-316.

Ceballos, F., Hernandez, M.A., Minot, N., \& Robles, M. (2015) Grain Price and Volatility Transmission from International to Domestic Markets in Developing Countries, World Development, 94, 305-320.

Chen, X., Kontonikas, A., and Montagnoli, A. (2012) Asset prices, credit and the business cycle, Economic letters, 117, 857-861.

Cosslett, S. R., and Lee, L. F. (1985) Serial Correlation in Discrete Variable Models, Journal of Econometrics, 27, 79-97.

Diebold, F. X., Lee, J. H., and Weinbach, G. C. (1994) Regime switching with time-varying transition probabilities, in C. Hargreaves (ed.), Nonstationary Time Series Analysis and Cointegration, Oxford: Oxford University Press, 283-302.

Edwards, S., and Susmel, R. (2003) Interest-Rate Volatility in Emerging Markets, The Review of Economics and Statistics, 85(2), 328-348, May.

Engel, C., and Hakkio, C. S. (1993) Exchange rate regimes and volatility, Economic Review, Federal Reserve Bank of Kansas City, Q III, 43-58.

Filardo, A. (1994) Business-Cycle Phases and Their Transitional Dynamics, Journal of Business \& Economic Statistics, 12(3), 299-308.

Geoffrey S. B. (2008) Livestock Feed Costs: Concerns and Options, CRS Report for Congress, available at www.research.policyarchive.org/18982.pdf.

Goldfeld, S. M., and Quandt, R. E. (1973) A Markov Model for Switching Regressions, Journal of Econometrics, 1(1), 3-16.

Hamilton, J. D. (1989) A new approach to the economic analysis of nonstationary time series and the business cycle, Econometrica, 57(2), 357-384.

Hamilton, J. D., and Susmel, R. (1994) Autoregressive conditional heteroskedasticity and changes in regime, Journal of Econometrics, 64(1-2), 307-333.

Johnson, C. (2018) Feeding Market Beef, Colorado State University Cooperative Extension and Department of Animal Sciences, Retrieved 14 January 2019, available at https://extension. unh.edu/resources/files/Resource002288_Rep3366.pdf.

Lawrence J. D., Mintert, Anderson, J.D., and Anderson. D.P. (2008) Feed Grains and Livestock: Impacts on Meat Supplies and Prices, Choices, 23(2), 11-15.

Lee, L., and Porter, R. (1984) Switching Regression Models with Imperfect Sample Separation Information--With an Application on Cartel Stability, Econometrica, 52(2), 391-418.

Matsushima J. K. (1979) Classification of Feeds. In: Feeding Beef Cattle, Advanced Series in Agricultural Sciences (vol. 7), Springer, Berlin, Heidelberg

Moolman, E. (2004) A Markov switching regime model of the South African business cycle, Economic Modelling, 21(4), 631-646

Moore, T., and Wang, P. (2007) Volatility in Stock Returns for New EU Member States: Markov Regime Switching Model, International Review of Financial Analysis, 16, 282-292. 
Reyes-Heroles, R., and Tenorio, G. (2017) Interest Rate Volatility and Sudden Stops: An Empirical Investigation, International Finance Discussion Papers, 1209, available at https://www.federalreserve.gov/econres/ifdp/files/ifdp1209.pdf

Schulte, H., and Musshoff, O. (2018) Market Structure of the Feed Industry in Germany: Causing Asymmetric Spatial Price Transmission?, Journal of Agricultural \& Food Industrial Organization, 17(1).

Shike, D. W. (2013) Beef Cattle Feed Efficiency, Driftless Region Beef Conference Proceedings, 31 January - 1 February 2013, Grand River Center, Dubuque, Iowa.

Tejeda, H. A., and Goodwin, B. K. (2009) Price volatility, nonlinearity and asymmetric adjustments in corn, soybean and cattle markets: implication of ethanol-driven shocks, Proceedings of the NCCC-134 Conference on Applied Commodity Price Analysis, Forecasting, and Market Risk Management. St. Louis, MO.

U.S. Department of Agriculture (2019) Agriculture Products Price Index, available at https://www.usda.gov/topics/data. 